\title{
Layout of an existing production unit by the Factorized Graph Method
}

\author{
NADIF Abdellah \\ University of Metz / LAEI \\ Ile du Saulcy, 57045 Metz Cedex 01, FRANCE \\ Tél.(33) 87-34-69-00, Fax (33) 87-34-69-36
}

\begin{abstract}
Facility layout is a process which aims to obtain an optimal arrangement of facilities in a workshop, in order to organize the production system and particularily to find the simplest way for the product from a workstation to another. It allows to decrease the tooling costs, the adjusting time and the handlings. The production management, which is concerned before everything with the scheduling tasks and with product flows, is thus decentralized on every production cell and therefore more flexible and more comfortable to achieve. The methodology developped in this paper, articulates about of 5 main stages. The combination of the 4 first stages permits an entirely automatic analysis and leads to the best theoretical assignation of work stations. The final stage is the definitive stage. On the basis of the result of the previous stages and using the software LAIA (Software for Aided layout of workshop), the work stations are layed out definitively in order to optimize, between others, the costs of handling taking into account the different constraints, for example the nuisance between work stations, walls, height, pillars...
\end{abstract}

\section{Keywords}

Workshop, layout, graph, Factorial Analysis, process plans

\section{INTRODUCTION}

The automation of manufacturing facilities (numerical control machines, robots, automaton,...) renders the production system of more and more complex. Consequently the success of the companies needs at the same time the coordination and the integration of the total production tool. The production is defined like a series of phases (manufacture, control, transport, storage,...). According to a recent survey (Cetim, 1991), when one quantifies the activities of production, the gains of productivity are composed as following:

$20 \%$ of total in ameliorating the existing,

$30 \%$ in automating,

$50 \%$ of the gains are in the evolution of the organization.

According to this survey, this assignation explains why the Japanese industry did not build its strategy of competitiveness exclusively on the automation of production means, but on the reduction of costs due to acceleration of the production flows (information and product flows). At present, the handling alone represents about $45 \%$ of the residence time of the product in the workshop. So an amelioration in this domain allows to shorten the delays and 
decrease the stocks. The number of defects can also decrease as a lot of them appear during the handling. A way to solve these problems is to ameliorate the layout of the production system by an optimal disposition of work stations in order to reduce as much as possible the distances of handling, while taking into account the geographical constraints (beams, walls, height,...) and functional constraints (nuisances for example) (Nadif, 1992). For these various reasons, we were brought to develop a methodology (Factorized Graph Method: MGF) in order to structure the data and to make it easy for the user, thanks to a Software for Aided layout of workshop: LAIA. This paper presents the result of the application of this method to the relocation of an area of a sheet-metal and brazier workshop, assigned to the manufacture of small sets (Figure1).

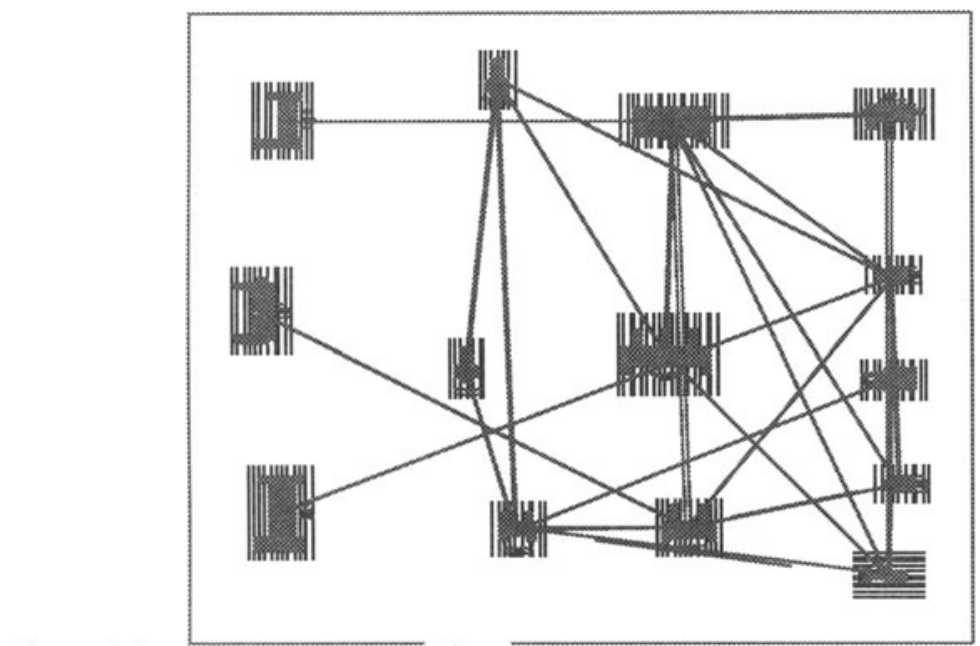

Figure 1 Area of workshop to be relocated (14 work stations)

\section{PROPOSED APPROCH}

The methodology proposed in this paper articulates about of 5 main stages:

1. Collection of data (process plans, floor-space of work stations, map of the building).

2. Generation of the flow matrix.

3. Estimation of missing data.

4. Factorial Analysis of the new flow matrix.

5. Definitive layout.

\subsection{Collection of data to analyze}

During of the analysis, one distinguishes two kinds of sets:

1. $G$ (set of process plans): $G=\left(g_{1}, g_{2}, \ldots, g_{i}, \ldots, g_{n}\right), g_{i}$ represents the $i^{\text {th }}$ process plans set. The analysis of process plans, allowed to identify 14 families of different products (Figure2), representative of the production of the considered area of workshop to relocate.

2. $M$ (set of the facilities): $M=\left(m_{1}, m_{2}, \ldots m_{j}, \ldots, m_{p}\right), m_{j}$ represents the th facility. 


\begin{tabular}{|c|c|c|c|c|c|c|c|c|c|c|c|c|c|c|}
\hline Process plans & $\mathrm{m} 1$ & $\mathrm{~m} 2$ & $\mathrm{~m} 3$ & $\mathrm{~m} 4$ & $\mathrm{~m} 5$ & $\mathrm{~m} 6$ & $\mathrm{~m} 7$ & $\mathrm{~m} 8$ & $\mathrm{~m} 9$ & $\mathrm{~m} 10$ & $\mathrm{~m} 11$ & $\mathrm{~m} 12$ & $\mathrm{~m} 13$ & $\mathrm{~m} 14$ \\
\hline g1 & 1 & & & & & & & 2 & & 3 & & & & \\
\hline g2 & & & 1 & 2 & & & & & & & & & 3 & \\
\hline g3 & & 1 & & & & & & & & & 2 & 3 & & \\
\hline g4 & & & 1 & & & 2 & & & & 3 & & & & \\
\hline g5 & & 1 & & & & & 2 & & & & 3 & & & \\
\hline g6 & & 1 & & & 3 & & & & & & 2 & & & \\
\hline g7 & & & 1 & 2 & & & & & & & & & & \\
\hline g8 & & & 1 & 2 & & & 3 & & & & & & & 4 \\
\hline g9 & 1 & & & & & & & & & & 2 & & & \\
\hline g10 & & 1 & & 2 & & & & & & & & & & \\
\hline g11 & & 1 & & 2 & & & & 4 & & & 3 & & & \\
\hline g12 & & & & & & 1 & & & & 2 & & & & \\
\hline g13 & & & & & & 1 & & & 2 & 3 & & & & \\
\hline g14 & 1 & & & & 2 & & & & & & 3 & 4 & & \\
\hline
\end{tabular}

Figure 2 Table of process plan data. It represents for each product $\mathrm{g}_{\mathrm{i}}$ the work stations that it as occupied successively (example: $\mathrm{g}_{6}\left(\mathrm{~m}_{2}, \mathrm{~m}_{11}, \mathrm{~m}_{5}\right)$ )

\subsection{Generation of the flow matrix}

From a mathematical point of view, one could represent the data under the form of a graph $\Gamma$, defined by a couple $(\mathrm{M}, \mathrm{U})$ where:

- $\mathrm{M}$ is the set of nodes of the graph (the 14 work stations of the area of the workshop)

- $\mathrm{U}$ is a part of $\mathrm{M}^{2}$ called the set of arcs (the flows between the work stations).

We consider $U$ like a set of links since one is not interested into the orientation of arcs. The value of a link between two nodes $i$ and $j$ is noted $u(i, j)$. It is defined as:

- $u(i, j)=1$ if it exists a junction between $i$ and $j$ (that is if there is at least one product which goes directly from work station $m_{i}$ to work station $m_{j}$ )

- $u(i, j)$ not defined otherwise. The figure 3 represents the flow matrix $u(i, j)$.) expressing the links between the 14 machines of the workshop area.

\begin{tabular}{lllllllllllllll}
\hline & $\mathrm{m} 1$ & $\mathrm{~m} 2$ & $\mathrm{~m} 3$ & $\mathrm{~m} 4$ & $\mathrm{~m} 5$ & $\mathrm{~m} 6$ & $\mathrm{~m} 7$ & $\mathrm{~m} 8$ & $\mathrm{~m} 9$ & $\mathrm{~m} 10$ & $\mathrm{~m} 11$ & $\mathrm{~m} 12$ & $\mathrm{~m} 13$ & $\mathrm{~m} 14$ \\
\hline $\mathrm{m} 1$ & & & & & 1 & & & 1 & & & 1 & & & \\
$\mathrm{~m} 2$ & & & & 1 & & & 1 & & & & 1 & & & \\
$\mathrm{~m} 3$ & & & & 1 & & 1 & & & & & 1 & & 1 & \\
$\mathrm{~m} 4$ & & 1 & 1 & & & & 1 & & & & 1 & & & \\
$\mathrm{~m} 5$ & 1 & & & & & & & & 1 & 1 & & & & \\
$\mathrm{~m} 6$ & & & 1 & & & & & & & & 1 & & & 1 \\
$\mathrm{~m} 7$ & & 1 & & 1 & & & & & & 1 & 1 & & & \\
$\mathrm{~m} 8$ & 1 & & & & & 1 & & & & 1 & & & & \\
$\mathrm{~m} 9$ & & & & & & 1 & & 1 & 1 & & & & & \\
$\mathrm{~m} 10$ & & & & & 1 & & 1 & 1 & & & & 1 & & \\
$\mathrm{~m} 11$ & 1 & 1 & & 1 & 1 & & & & & & 1 & & & \\
$\mathrm{~m} 12$ & & & & & & & & & & & & & & \\
$\mathrm{~m} 13$ & & & & 1 & & & 1 & & & & & & \\
$\mathrm{~m} 14$ & & & & & & & & & & & &
\end{tabular}

Figure 3 Flow Matrix $\mathrm{U}(\mathrm{u}(\mathrm{i}, \mathrm{j}))$ describing the links existing between the 14 work stations 


\subsection{Factorial Analysis}

The methods of Factorial Analysis are methods of graphic representation of data (Diday, 1992). They allow to operate a reduction of dimension of the space of work. Indeed, these descriptive methods aim at representing a set of points defined in a p dimensional space into a $\mathrm{q}$ dimensional space with $\mathrm{p}>\mathrm{q}$, while maintaining as much information as possible, in particular the distances between the points. The figure 4 shows an example of transformation of one space with three dimensions into a space with two dimensions.

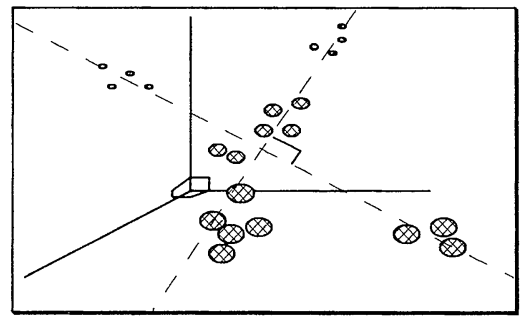

Figure 4 Representation of data defined in three dimensional space in factorial plane defined by two factorial axes.

The quality of this representation is defined by the explanation rate $\tau$ which is equal to the sum of the inertie of the two axes defining the plane. the more $\tau$ is close to $100 \%$, the best is the representation (Figure8).

It exists several types of methods of Factorial Data Analysis (Benzécri, 1984). These methods differ by the nature of the data to analyze and by the measurements of proximity that they use. Our choice has been the Principal Component Analysis on a Distance Table (AFTD) for two reasons: on one hand the nature of data does not intervene and on other hand the AFTD allows to treat any table obtained using a distance or in general using a dissimilarity measure. The algorithm of the AFTD is composed of three stages described in figure 5.

- Stage $\mathbf{N}^{\bullet} 1$ : Initialization of the distance matrix [d] (of general term $\boldsymbol{d}_{i j}$ ): $\boldsymbol{d}_{i j}$ represents the distance between the object $\omega_{i}$ and the object $\omega_{j}$.

- Stage $\mathrm{N}^{\bullet} 2$ : Calculation of the matrix $[\sigma]$ of general term $\sigma_{\mathrm{ij}}$ : $\sigma_{i j}=-\frac{1}{2}\left(d_{i j}^{(2)}-d_{i .}^{(2)}-d_{j}^{(2)}+d_{. .}^{(2)}\right)$ with: $d_{i .}^{(2)}=\sum_{j=1}^{n} d_{i j}^{2}, d_{j}^{(2)}=\sum_{i=1}^{n} d_{i j}^{2}$ and $d_{.}^{(2)}=\sum_{i=1}^{n} \sum_{j=1}^{n} d_{i j}^{2}$

- Stage N*3: Calculation of eigenvalues $[\lambda]$ and eigenvectors $[v]$. The eigenvectors are classified by decreasing order of eigenvalues.

The new coordinates of objects $\omega_{i}$ are expressed by the following relation:

$$
\omega_{i}=\sqrt{\lambda_{i}}\left(v_{i 1}, v_{i 2}, \ldots, v_{i n}\right) \text {. }
$$

The rate of explanation of $\mathrm{i}^{\text {th }}$ factorial axis is: $\tau_{i}=\frac{\lambda_{i}^{2}}{\sum_{k=1}^{n} \lambda_{k}^{2}}$ 


\subsection{Estimation of missing data}

To apply an AFTD, one has to dispose of a complete dissimilarity matrix. In our situation some nodes are not bound directly (abscence of flow between the corresponding work stations). In this case, we propose to complete the missing data using an algorithm permitting the research of the shortest path between nodes. The Floyd algorithm (Gaudel, 1987) (Figure6) was selected for its simplicity (but other algorithms of research of shortest path can be used as well). This algorithm creates a new matrix $D$ of general term $d(i, j)$.

This way, one obtains a symmetrical distance matrix $\mathrm{D}$ where all terms are positive (Figure7).

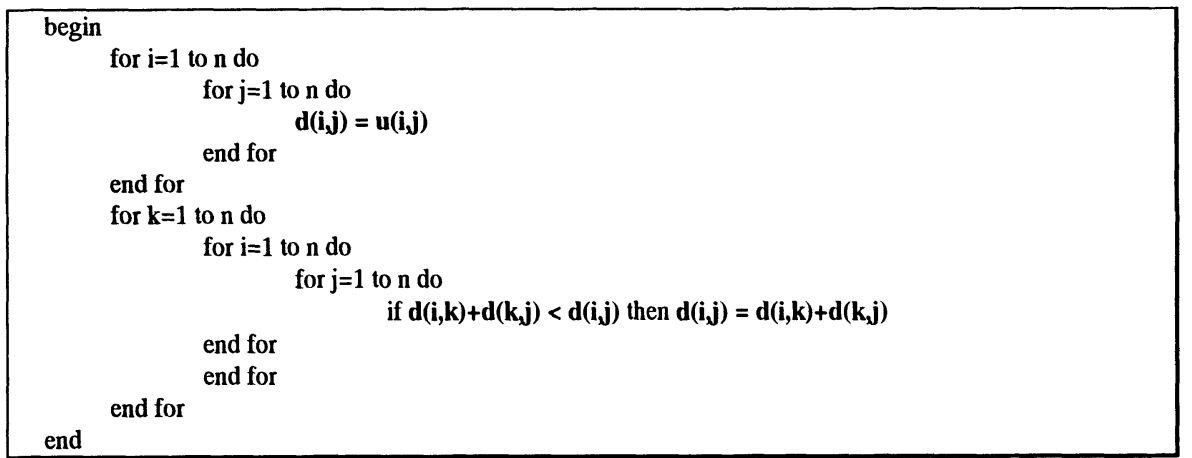

Figure 6 Floyd Algorithm for the research of shortest path

\begin{tabular}{lllllllllllllll}
\hline & $\mathrm{m} 1$ & $\mathrm{~m} 2$ & $\mathrm{~m} 3$ & $\mathrm{~m} 4$ & $\mathrm{~m} 5$ & $\mathrm{~m} 6$ & $\mathrm{~m} 7$ & $\mathrm{~m} 8$ & $\mathrm{~m} 9$ & $\mathrm{~m} 10$ & $\mathrm{~m} 11$ & $\mathrm{~m} 12$ & $\mathrm{~m} 13$ & $\mathrm{~m} 14$ \\
\hline $\mathrm{m} 1$ & 0 & 2 & 3 & 2 & 1 & 3 & 2 & 1 & 3 & 2 & 1 & 2 & 3 & 3 \\
$\mathrm{~m} 2$ & 2 & 0 & 2 & 1 & 2 & 3 & 1 & 2 & 4 & 3 & 1 & 2 & 2 & 2 \\
$\mathrm{~m} 3$ & 3 & 2 & 0 & 1 & 3 & 1 & 2 & 3 & 2 & 2 & 2 & 3 & 2 & 3 \\
$\mathrm{~m} 4$ & 2 & 1 & 1 & 0 & 2 & 2 & 1 & 2 & 3 & 3 & 1 & 2 & 1 & 2 \\
$\mathrm{~m} 5$ & 1 & 2 & 3 & 2 & 0 & 4 & 2 & 2 & 4 & 3 & 1 & 2 & 3 & 3 \\
$\mathrm{~m} 6$ & 3 & 3 & 1 & 2 & 4 & 0 & 3 & 2 & 1 & 1 & 3 & 4 & 3 & 4 \\
$\mathrm{~m} 7$ & 2 & 1 & 2 & 1 & 2 & 3 & 0 & 2 & 4 & 3 & 1 & 2 & 2 & 1 \\
$\mathrm{~m} 8$ & 1 & 2 & 3 & 2 & 2 & 2 & 2 & 0 & 2 & 1 & 1 & 2 & 3 & 3 \\
$\mathrm{~m} 9$ & 3 & 4 & 2 & 3 & 4 & 1 & 4 & 2 & 0 & 1 & 3 & 4 & 4 & 5 \\
$\mathrm{~m} 10$ & 2 & 3 & 2 & 3 & 3 & 1 & 3 & 1 & 1 & 0 & 2 & 3 & 4 & 4 \\
$\mathrm{~m} 11$ & 1 & 1 & 2 & 1 & 1 & 3 & 1 & 1 & 3 & 2 & 0 & 1 & 2 & 2 \\
$\mathrm{~m} 12$ & 2 & 2 & 3 & 2 & 2 & 4 & 2 & 2 & 4 & 3 & 1 & 0 & 3 & 3 \\
$\mathrm{~m} 13$ & 3 & 2 & 2 & 1 & 3 & 3 & 2 & 3 & 4 & 4 & 2 & 3 & 0 & 3 \\
$\mathrm{~m} 14$ & 3 & 2 & 3 & 2 & 3 & 4 & 1 & 3 & 5 & 4 & 3 & 3 & 3 & 0 \\
\hline
\end{tabular}

Figure 7 Matrix D, resulting of treatment using the Floyd algorithm.

The unknown data are thus estimated by the value of the shortest path which corresponds to the smallest number of links. As this matrix is defined and positive, there is an Euclidian representation of the set of nodes which respects the distances between the points. This is obtained by the use of the AFTD, described in the previous paragraph. 


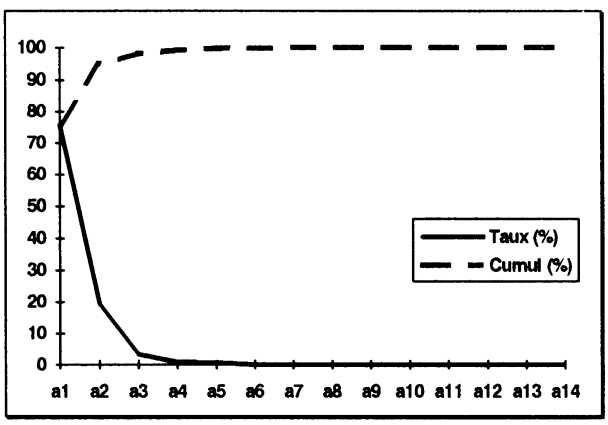

Figure 8 Representation of the rate of explanation of the factorial axes.

The figure 9 represents the projection of 14 facilities on the first factorial plane, constituting the theoretical location of the work stations.

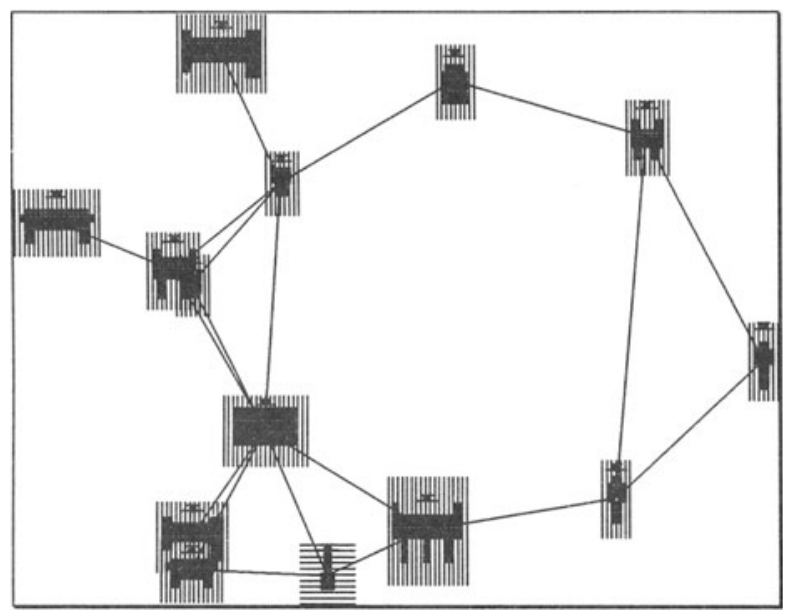

Figure 9 Theorical location of the workshop,

Although it is not a picture entirely faithful of the reality, this graphic representation leads to an apparent distribution of work stations which can be analysed by the human eye.

\subsection{Definitive layout}

So that this approach can be used easily, we developped a graphic software for aided layout of the workshop (LAIA). This software was the factorial coordinates of the different work stations, obtained by automatic treatment during the previous stage, floor-space of the work stations, the map and of the area to be relocated. The input/output data of LAIA is shown on the figure 10. The software LAIA aids the user to achieve the definitive layout in facilitating, in an interactive manner, the displacement, the rotation or the permutation of the work stations (Figure11). 


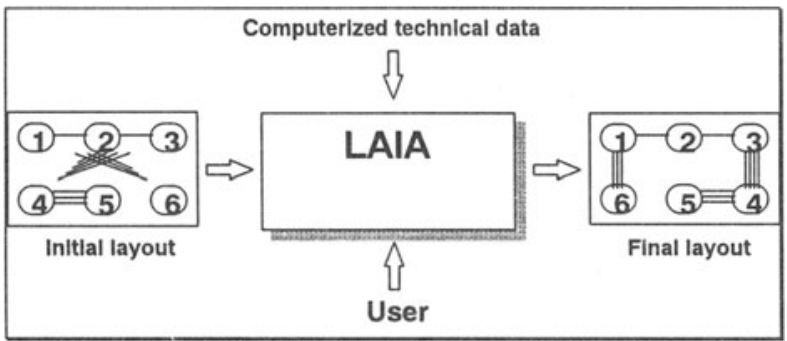

Figure 10 Different input/output data of LAIA

\section{Menu 1}

1. Permutation of 2 work stations

2. Identification of a work station ...

3. Drawing of the flow between work stations

4. Zoom

1. Moving the work station

2. Rotating the work station

3. Informations of the work station

Figure 11 Some Functions of LAIA

The figure 12 represents the result of the relocation of the area of workshop. The comparison of figures 1 and 12 shows the simplification of the product flow due to the application of the method MGF described in this paper.

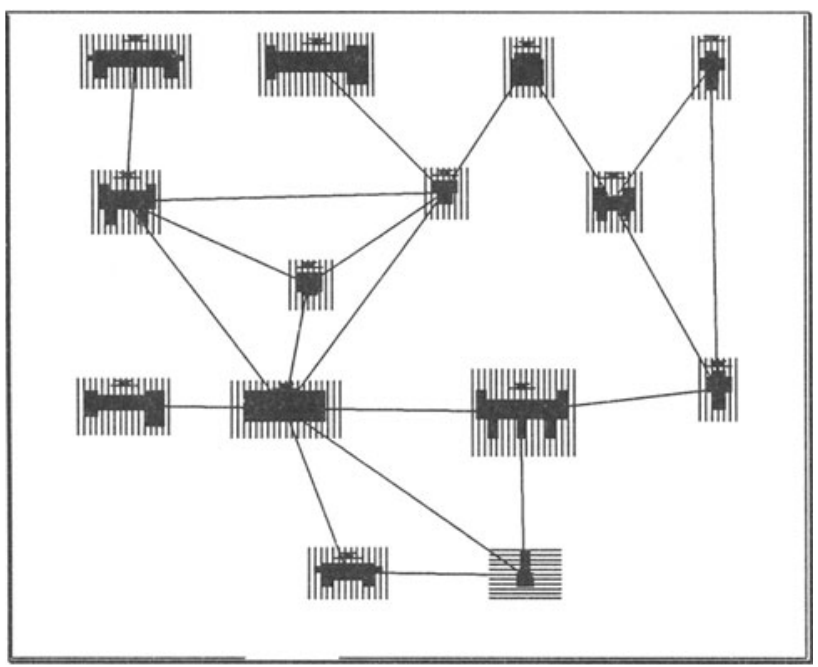

Figure 12 Result of the relocation of the workshop area. 


\section{CONCLUSION}

The methods published in the literature meet large difficulties as soon as the shop to relocate contains an elevated number of work stations $(>12)$ (Lavelle, 1985). The methodology developed in the present paper allows to structure the manufacturing data in order to render the production tools as most efficient as possible. This methodology has been computerized. This permits a treatment in the day if the data to analyze is ready. When using classical algorithms for workshop layout, one can see that their result cannot be considered as a global optimal solution, as it is strongly dependant on initialization parameters which are often difficult to quantify. On the contrary the MGF needs no initialization and leads to unique result. At present, we are working on the coupling of the Factorized Graph Method (MGF), and of the Software for Aided layout of workshop (LAIA) with a tool of automatic classification (Mutel, 1989) for the formation of manufacturing cells, in order to perform intra cell and inter cells layout.

\section{REFERENCES}

Cetim documentation, April 1991.

Nadif, A. and Anciaux, D. (1992), New approach to manufacturing system layout, WISU Verlag Aachen, CIRP, Manufacturing Systems, vol. $21, \mathrm{~N}^{\bullet} 4$.

Diday, E., Lemaire, J., Pouget, J. and Testu, F. (1982), Eléments d'analyse des données. Bordas

Benzécri, J.-P. and Benzécri, F. (1984), Pratique de l'analyse des données, Dunod

Gaudel, M.-C., Soria, M. and Froidevaux, C.(1987), Type de données et algorithmes. Edition didactique INRIA

Lavelle, I. and Roucairol, C. (1985), Parallel branch and bound algorithm, Euro VIII, Bologne, Italie.

Mutel, B. Nadif, A. and Costantini, M. (1989), Integration of production departments by generalized Group Technology concept, Edited by AT\&T BELL LABORATORIES AND UNIVERSITY OF ILLINOIS AT URBANA CHAMPAIGN, DE-VOL.21, PED-vol.36, 1989, pages 93 to 99 . 